\title{
Formações de Clusters de Eficiência nos Mercados Futuros Agropecuários Mundiais de Soja ${ }^{1,2}$
}

\author{
Marcos Aurelio Rodrigues ${ }^{3}$ e João Gomes Martines Filho ${ }^{4}$
}

Resumo: Investigou-se a eficiência e formações de clusters nos contratos futuros do complexo soja (soja, farelo de soja e óleo de soja) negociados nas bolsas de commodities: argentina, brasileira, chinesa, indiana, japonesa, norte-americana e sul-africana. Com base na métrica obtida por distância euclidiana de razões de variância, evidenciaram-se dependências similares dos mercados, as quais podem ser interpretadas como efeito espraiamento da eficiência informacional. Os agentes devem, portanto, manter percepções em relação aos diversos mercados devido às sinalizações interdependentes dos preços.

Palavras-chaves: Eficiência de mercado, análise de cluster, agropecuário.

Abstract: We analyzed the efficiency and the presence of clusters in the soybean complex future contracts (soybean, soybean meal and soybean oil) traded in the following future markets: Argentina (MTB), Brazil (BVMF), China (DCE), India (NCD), Japan (TKT), US (CBT) and South-Africa (SAF). Based on the metrics obtained by Euclidian distances of variance ratios, similar dependencies were found for all markets. The results suggest informational efficiency spread. Therefore, agents shall maintain perceptions over several international markets, given the interdependence found for prices in separate future markets.

Key-words: Market efficiency, clustering, agricultural.

1. Data de submissão: 30 de maio de 2016. Data de aceite: 19 de março de 2017.

2. Os autores agradecem aos comentários e sugestões de Alexandre Florindo Alves, Daniel Henrique Dario Capitani, João Afonso Bastos, José César Cruz Júnior e Paulo Fernando Cidade de Araújo.

3. Tribunal de Justiça do Estado do Paraná, Curitiba, PR, Brasil. E-mail: rodriguesmarcosaurelio@gmail.com

4. Escola Superior de Agricultura "Luiz de Queiroz", Universidade de São Paulo, Piracicaba, SP, Brasil. E-mail: martines@usp.br 


\section{Introdução}

Os agentes dos mercados de commodities agropecuárias utilizam como balizadores de preços os contratos futuros negociados nas tradicionais bolsas de países desenvolvidos. No entanto, com o recente crescimento negocial dos contratos oferecidos pelas bolsas nos países em desenvolvimento, em particular nos mercados asiáticos chineses e indianos, esses agentes também possuem, nos novos mercados, a possibilidade de executarem suas operações especulativas, de hedge, arbitragem e, consequentemente, apresentam-se como novo difusor informacional de preços.

Uma vez que os mercados consolidados são utilizados como referência na descoberta de preços pelos agentes em todo o mundo, esses devem refletir as informações desses mercados de maneira eficiente. Diz-se que um mercado é informacionalmente eficiente na forma fraca, o qual reflete todas as informações em seus preços passados (FAMA, 1970). Portanto, sob esse comportamento, em um mercado eficiente não há possibilidade preditiva somente com os preços históricos.

Há importância em estudar a hipótese de eficiência de mercado, pois os mercados eficientes funcionam como alternativa à intervenção governamental na gerência do risco de preços dos agentes do mercado. Além de possibilitar redução de risco, por meio de operações de hedge, os produtores e comerciantes dos produtos agropecuários podem utilizar desses mercados para descoberta de preços. Além disso, o funcionamento informacional dos mercados futuros, tanto em bolsas dos países desenvolvidos como em desenvolvimento, é relevante aos agentes que fazem transações internacionais com ativos físicos adjacentes negociados.

Uma vez que os mercados agropecuários mundiais são interligados e as informações estão disponíveis a todos os agentes, espera-se que os retornos dos mercados futuros para os mesmos ativos, bem como seus derivados, tenham comportamentos similares. Diante disso, há uma possível formação de aglomerações das séries de retornos, dadas as características de dependência serial.

Os estudos sobre a eficiência em mercados agropecuários foram revistos nos surveys de Garcia, Hudson e Waller (1988), Garcia e Leuthold (2004). Nota-se que nesses surveys, as commodities agropecuárias consideradas foram as negociadas em países desenvolvidos, cujos mercados podem ser considerados como consolidados. Ademais, a maioria dos estudos testou a eficiência dos contratos norte-americanos, com evidências heterogêneas à hipótese de eficiência dos mercados. Na visão de Kumar e Pandey (2013), infelizmente, poucos trabalhos empíricos investigam a eficiência nos mercados futuros emergentes 
de commodities agropecuárias. Os estudos nos mercados futuros agropecuários dos países em desenvolvimento têm características semelhantes, tanto metodologicamente como em evidências discrepantes para os mesmos ativos.

Tais evidências heterogêneas podem ser atribuídas ao período de análise e ao poder estatístico dos testes empregados, sendo que estes com predomínio da abordagem cointegrante para a hipótese conjunta de enviesamento e eficiência de mercado. Ressalta-se que, ao fazerem uso dessa abordagem, deixam de tratar de forma específica se os mercados condizem com a eficiência, a exemplo de testes para conformidade a um processo martingal, conforme sugere Jarrow e Larsson (2012).

O objetivo deste estudo é investigar a eficiência dos mercados de contratos futuros de soja, desenvolvidos e em desenvolvimento, sob a hipótese fraca de Fama (1970). Em particular, objetiva-se testar a hipótese de sequência de diferença martingal das séries de retornos desses contratos e analisar as formações de clusters de eficiência nos mercados futuros de soja e seus derivados: farelo e óleo. Diferencia-se da literatura por utilizar-se da recente métrica proposta por Bastos e Caiado (2014), a qual permite avaliar a interdependência das séries temporais de retornos futuros com foco na previsibilidade. Distingue-se, também, por ser um compressivo estudo dos principais mercados futuros do complexo soja (soja, farelo de soja e óleo de soja) negociados nas seguintes bolsas: Bolsa de Valores, Mercadorias e Futuros (BVMF), Chicago Board of Trade (CBT), Dalian Commodity Exchange (DCE), Mercado a Término de Rosario (ROFX), National Commodities and Derivatives Exchange (NCD), South African Futures Exchange (SAF) e Tokyo Commodity Exchange (TKT), entre 2011 e 2013.

\section{Eficiência dos mercados}

Chama-se de eficiente o mercado no qual os preços sempre "refletem completamente" as informações disponíveis (FAMA, 1970). Disposta em seu survey, essa definição clássica para um mercado eficiente é subdividida em outras três hipóteses, ${ }^{5}$ que refletem de forma ascendente o conjunto informacional. O conjunto de informações na hipótese fraca compreende somente os preços históricos. $\mathrm{Na}$ semiforte são inclusas outras informações publicamente disponíveis. E, na forte, estão incluídas informações não públicas.

$\mathrm{Na}$ primeira hipótese, a qual é o objeto deste estudo, são, portanto, incorporadas todas as informações relevantes nos preços. Assim, segundo Ross (2004), transmite-se a ideia de que os preços resultam das decisões individuais dos agentes e dependem das informações subjacentes a essas decisões. Como corolários: i) os retornos futuros dos ativos dependem das novas informações transmitidas ao mercado e não das informações correntes, ii) um agente sujeito a um conjunto informacional igual ou inferior ao contido nos preços não possui capacidade preditiva de novas informações, logo não é hábil a obter retornos superiores ao mercado.

Acredita-se comumente que, utilizando-se dessa definição de Fama (1970), para testar a hipótese de eficiência de mercado, deve-se primeiro especificar um modelo de equilíbrio (JARROW e LARSSON, 2012). De acordo com os autores chama-se esse problema de "bad-model" ou hipótese conjunta. No entanto, demonstraram que é possível testar a eficiência de mercado sem especificar um modelo de equilíbrio em particular. Suas proposições têm como base a literatura na qual a existência de oportunidades de arbitragem rejeita a eficiência de mercado. E, portanto, identificar oportunidades de arbitragem não requer a especificação de um modelo em particular. Assim, suas demonstrações à hipótese de eficiência perpassam o problema de "bad-model" e, com testes sob a hipótese martingal, testa-se também a hipótese de eficiência de mercado.

Utilizando-se a exemplificação de Escanciano e Lobato (2009b) para o conceito martingal e para

5. Fama (1970) credita a Harry Roberts essa subdivisão à eficiência dos mercados. 
a sequência de diferença martingal, tem-se que $X_{t}$ forma um martingal quando $E\left[X_{t} \mid X_{t-1}, X_{t-2}\right.$, $\left.\ldots=X_{t-1}\right]$, quase certamente. Conforme ressaltado pelos autores, é mais simples lidar com as primeiras diferenças, $Y_{t}=X_{t}-X_{t-1}, \operatorname{logo}, Y_{t}$ segue uma sequência de diferença martingal quando $E\left[Y_{t} \mid Y_{t-1}, Y_{t-2}, \ldots=0\right]$, quase certamente. De forma mais geral, a hipótese de diferença martingal se mantém para uma série temporal estacionária de números reais $\left\{Y_{t}\right\}_{t=-\infty}^{\infty}$, quando a seguinte restrição para o momento condicional se mantém quase certamente:

$$
E\left[Y_{t} \mid Y_{t-1}, Y_{t-2}, \ldots\right]=\mu, \mu \in \mathbb{R} .
$$

Essa hipótese generaliza a noção de sequência de diferença martingal ao permitir que a média não condicional de $Y_{t}$ seja diferente de zero ou desconhecida. Além disso, estabelece que o melhor preditor dos valores futuros de uma série temporal é a esperança não condicional, dado o conjunto informacional passado e corrente. Logo, implica que as informações passadas e correntes não são úteis à predição dos valores futuros de uma sequência de diferença martingal.

Segundo Ross (2004), a eficiência fraca de mercado implica que os retornos sejam não correlacionados serialmente no tempo e, naturalmente, os retornos são não correlacionados com quaisquer combinações lineares dos retornos passados quando as correlações são calculadas com o uso de probabilidades martingal. Implicação, esta, também ressaltada por Escanciano e Lobato (2009b), conforme segue. Seja $I_{t}=\left\{Y_{t}, Y_{t-1}, \ldots\right\}$ o conjunto informacional em $t$ e $\mathcal{F}_{t}$ a $\sigma$-algebra gerada por $I_{t}$. A equivalência seguinte é fundamental, pois formaliza a propriedade característica de uma sequência de diferença martingal: $Y_{t}$ é linearmente não previsível dadas quaisquer transformações $w\left(I_{t-1}\right)$, lineares ou não lineares do passado, isto é,

$$
E\left[Y_{t} \mid I_{t-1}\right]=\mu \text { q.c. } \mu \in \mathbb{R} \Leftrightarrow E\left[\left(Y_{t}-\mu\right) w\left(I_{t-1}\right)\right]=0,
$$

para qualquer função ponderada $w($.$) de \mathcal{F}_{t-1}$-mensurável. Portanto, os testes à eficiência podem ser procedidos com base na análise da dependência, linear ou não linear, das séries de retorno.
Os testes para a hipótese de eficiência de mercado são úteis como primeiro passo na avaliação da utilidade social dos mercados futuros (KELLARD et al., 1999). Essa utilidade da eficiência nos mercados futuros se faz presente diante das implicações aos agentes de comercialização, investidores, governos, reguladores dos mercados e às próprias bolsas. Sendo eficientes, podem propiciar descoberta de preços, redução dos custos de transação, gestão de estoques, assim como a gestão dos riscos inerentes às respectivas cadeias produtivas.

Os mercados futuros devem ser eficientes para poderem refletir, com acurácia, as expectativas futuras e o valor de equilíbrio de oferta e demanda dos participantes. Dessa forma, a eficiência nos mercado futuros agrícolas é importante tanto aos agentes de comercialização e produção como aos governos. Para os agentes de comercialização e produção, permite gerência efetiva dos riscos de preços. Além disso, em mercados eficientes, há reflexo positivo nos custos de transação dos agentes, pois podem negociar com baixos custos de transação devido à menor quantidade de buscas por informações. Para os governos, um mercado eficiente significa melhor alternativa às suas intervenções (SAHAI, 2014; WANG e KE, 2005; ARUGA, 2011).

Com menores intervenções governamentais, os mercados futuros devem ser vistos como balizadores nas tomadas de decisão e gestão dos estoques aos agentes de comercialização e processadores. Ao tomarem essas decisões, os produtores podem utilizar os sinais contidos nos preços para ajustarem suas produções, comercializações e riscos nas suas atividades, possibilitando a mitigação dos potenciais riscos, ao fazer uso apropriado dos instrumentos de hedging. Assim, permite melhor gerência de estoque e de hedge ao se utilizarem das sinalizações de um mercado eficiente (ZHENG e WANG, 2013).

Os mercados futuros podem fornecer sinalizações de preços, acessíveis e úteis, para orientar as decisões de produção, de comercialização e de gestão do risco de preços. Segundo Kumar e Pandey (20013) e Zheng e Wang (2013), para que 
isso ocorra, os mercados futuros devem estar de acordo com a hipótese de eficiência de mercado, proporcionando a descoberta de preços e as funções de hedge. Entretanto, ressaltam que a falta de fluxo informacional adequado pode afetar o processo de descoberta de preços e a gestão de riscos.

Os mercados emergentes, nos quais os derivativos são relativamente recentes, têm características diferentes se comparados aos mercados desenvolvidos e, nos estágios iniciais de desenvolvimento, apresentam certa ineficiência em seus contratos (KUMAR e PANDEY, 2013). Zheng e Wang (2013) levantaram algumas características que podem influenciar na não eficiência desses mercados como: características estruturais diferentes, nível de participação de agentes, assim como regulações ou supervisões governamentais. Os emergentes são caracterizados por baixa liquidez, poucos negócios, oferecerem pouco período amostral para pesquisa e, consequentemente, exibirem baixa correlação com mercados desenvolvidos, não normalidade, previsibilidade e elevada volatilidade (KUMAR e PANDEY, 2013). Portanto, a possível formação de clusters nos mercados do complexo soja se justifica devido a essas dessemelhanças ressaltadas pelos autores entre mercados desenvolvidos e em desenvolvimento.

Conforme dados do United States Department of Agriculture (USDA), no período em análise, destacaram-se Estados Unidos, Brasil e Argentina como principais produtores de soja, com representatividade de $80 \%$ da produção mundial e $86 \%$ do volume exportado. Em conjunto com a China, estes quatro países representaram $76 \%$ do consumo mundial e, para atender o consumo chinês, este país teve participação de $62 \%$ das importações mundiais.

Para o óleo de soja, a produção desses quatro países somou $78 \%$, enquanto o consumo doméstico dos quatro maiores consumidores foi de $67 \%$, composto, além de China, Brasil e EUA, pela Índia. Em relação às transações internacionais, destacaram-se as participações da China e da Índia nas importações, com $32 \%$ e da Argentina, com $44 \%$

6. Dados disponíveis na Tabela 1A. do volume exportado. Comparativamente, os maiores países produtores apresentaram soma percentual similar para o farelo de soja, em relação ao óleo de soja e, a Argentina, de forma análoga, também teve a maior participação na exportação deste produto.

Apesar de terem listados contratos de soja em bolsas, Japão e África do Sul não estão entre os países mais relevantes nesses aspectos abordados. A exceção foi o Japão como quarto maior importador de soja, com participação de apenas 2,7\%.

\subsection{Evidências empíricas}

Os estudos iniciais à hipótese de eficiência dos mercados agropecuários utilizaram-se de testes sob dependência serial e análise espectral. Esses estudos foram revistos nos surveys de Garcia, Hudson e Waller (1988) e Garcia e Leuthold (2004) e, segundo os autores, apresentaram resultados não consensuais à hipótese de eficiência, em particular aos contratos futuros de soja e seus derivados. Esses estudos revistos verificaram a eficiência dos mercados futuros norte-americanos, os quais podem ser considerados como consolidados e desenvolvidos.

Apresentam-se na Tabela 1 estudos recentes à hipótese de eficiência de contratos futuros do complexo soja nesses mercados. Kellard et al. (1999) e Chinn e Coibion (2014) evidenciaram eficiência no longo prazo para o mercado futuro de soja. No entanto, Kellard et al. (1999) sugerem que no curto prazo houve evidência de não eficiência. McKenzie e Holt (2002) encontraram evidências favoráveis à eficiência do mercado norte-americano de farelo de soja, tanto no curto como no longo prazo.

Nota-se, portanto, discrepância nas evidências dos mercados norte-americanos, assim como demonstraram os surveys de Garcia, Hudson e Waller (1988) e Garcia e Leuthold (2004). Ademais, suas revisões não dispõem de contratos futuros em mercados emergentes. Os demais estudos dispostos na Tabela 1 tiveram como objeto de estudo os mercados futuros emergentes e em desenvolvimento. 
Tabela 1. Estudos empíricos sobre a eficiência dos mercados futuros do complexo soja

\begin{tabular}{cccccc}
\hline Bolsa & Autores & Contrato & Metodologia & Período & Evidência \\
\hline BVMF & Abitante (2008) & Soja & Cointegração & 2005 & Mista \\
BVMF & Fraga e Silva Neto (2011) & Soja & Cointegração & $2007-2008$ & Desfavorável \\
CBT & Kellard et al. (1999) & Soja & Cointegração & $1979-1996$ & Mista \\
CBT & McKenzie e Holt (2002) & Farelo de Soja & Cointegração & $1959-2000$ & Favorável \\
CBT & Chinn e Coibion (2014) & Soja & Cointegração & $1990-2012$ & Favorável \\
ROFX & Pacheco (2004) & Soja & Dependência serial & $1994-2002$ & Desfavorável \\
DCE & Peng et al. $(2006)$ & Óleo de soja & Cointegração & $2003-2006$ & Desfavorável \\
DCE & Wang e Ke (2005) & Soja & Cointegração & $1998-2002$ & Mista \\
DCE & Zheng e Wang (2013) & Soja & Cointegração & $2003-2010$ & Mista \\
NCD & Sahai (2014) & Óleo de soja & Cointegração & $2004-2014$ & Desfavorável \\
NCD & Kumar e Pandey (2013) & Soja & Cointegração & $2004-2008$ & Mista \\
TKT & Aruga (2011) & Soja & Cointegração & $2000-2008$ & Mista \\
\hline
\end{tabular}

Nota: Bolsa de Valores, Mercadorias e Futuros (BVMF), Chicago Board of Trade (CBT), Dalian Commodity Exchange (DCE), Mercado a Término de Rosario (ROFX), National Commodities and Derivatives Exchange (NCD), South African Futures Exchange (SAF) e Tokyo Commodity Exchange (TKT) - conforme ISO 10383 - Market Identifier Code. Optou-se por serem apresentadas apenas as evidências referentes à soja e seus derivados nesses estudos.

Fonte: Bloomberg.

Esses também apresentaram evidências discrepantes, assim como nos mercados desenvolvidos, conforme se pode observar a seguir.

De acordo com Zheng e Wang (2013), apesar de vasta literatura à eficiência em mercados desenvolvidos, os resultados encontrados podem não ser confirmados em mercados em desenvolvimento. Pois é razoável esperar que nos estágios iniciais de desenvolvimento de um mercado haja baixa eficiência. Segundo Kumar e Pandey (2013), os mercados emergentes são recentes e têm poucas observações, o que justifica a discrepância na quantidade de artigos efetuados nesses mercados e oferece oportunidade para investigar o questionamento quanto à sua eficiência.

Enquanto que Fraga e Silva Neto (2011) e Pacheco (2004) demonstraram evidências de não eficiência nos mercados de soja - brasileiros e argentinos - respectivamente, os demais estudos demonstraram evidências mistas nos mercados em desenvolvimento. Essas evidências mistas, favoráveis e desfavoráveis, deram-se em função da segmentação dos períodos de análise, frequências dos dados e contratos de diferentes vencimentos. Para os mercados futuros de óleo de soja - chineses e indianos - os resultados encontrados por Peng, Yong e Suo (2006) e Sahai (2014) foram desfavoráveis à hipótese de eficiência.
As evidências empíricas de Peng, Yong e Suo (2006) sugerem que os futuros de commodities na China não possuem poder de precificação internacional, com direção da influência dos preços ocorrendo dos mercados norte-americanos para o mercado local. Abitante (2008) demonstrou a existência de cointegração entre os preços à vista do mercado local da soja e os preços futuros norte-americanos. Conforme exposto por Aruga (2011), os mercados de soja são negociados em diversas bolsas e, portanto, há elevadas informações relevantes para esse produto. Assim, os mercados de soja podem exibir clusters informacionais devido a essa disseminação de informações contidas nos preços em diversas bolsas. E, também, devido à influência dos mercados internacionais, em particular dos mercados norte-americanos, nos mercados locais (emergentes).

Em relação à metodologia empregada pelos autores, houve predominância do método de cointegração nesses estudos recentes à hipótese de eficiência, diferente dos estudos iniciais, que verificaram a existência de dependências lineares e não lineares. Segundo Garcia e Leuthold (2004), os estudos passaram a adotar os modelos de correção de erro e testes de cointegração para verificar a hipótese conjunta de não enviesamento e eficiência de mercado. Após as noções 
sobre cointegração de Granger e Johansen, essa abordagem passou a ser predominante nos estudos sobre a eficiência dos ativos agropecuários, tanto nos estudos em mercados consolidados, dispostos em Garcia e Leuthold (2004), como nos estudos em mercados emergentes, dispostos na Tabela 1.

Conforme essa abordagem cointegrante, os estudos testaram a hipótese de uma relação de longo prazo, entre os preços à vista e futuros, de $[1,-1]$ sob o termo de correção de erro, e não, de forma específica, se os mercados futuros condizem com a eficiência. Dessa forma, os estudos deixaram de abordar, sob as séries temporais dos mercados futuros, as noções de processos em conformidade a um passeio aleatório e a um martingal, conforme advogam, por exemplo, os estudos de Fama (1970), Ross (2004), Escanciano e Lobato (2009b) e Jarrow e Larsson (2012).

\section{Agrupamento de eficiência dos mercados}

Nessa sessão, descrevem-se os passos metodológicos procedidos para a análise de agrupamentos de eficiência dos mercados futuros do complexo soja. Primeiramente, computam-se as razões de variância propostas por Chow e Denning (1993) e Belaire-Franch e Contreras (2004). Com base nessas razões de variância, calcula-se métrica proposta por Bastos e Caiado (2014), que, por sua vez, possibilita proceder com a análise hierárquica de clusters de eficiência.

\subsection{Razão de variância}

A metodologia de razão de variância consiste em testar a hipótese de sequência martingal, explorando o fato que a variância dos incrementos de uma sequência martingal é linear em todos os intervalos amostrais. A razão de variância na defasagem $k$ é definida como a razão entre $(1 / k)$ -ésima da $k$-ésima diferença em relação à vari- ância da primeira diferença. Portanto, espera-se que, para uma sequência martingal, a variância calculada para cada intervalo de defasagens individuais $k=2,3 \ldots$ deve ser igual à unidade (BELAIRE-FRANCH e CONTRERAS, 2004).

De acordo com Belaire-Franch e Contreras (2004), apesar de usualmente averiguarem várias defasagens nas estatísticas de razão de variância no contexto do teste de Lo e MacKinlay (1988), cuja hipótese nula é rejeitada para alguma defasagem $k$, Chow e Denning (1993) ressaltam que esse procedimento sequencial leva ao sobredimensionamento dos testes. Conforme apontado por Wright (2000), utilizar-se de vários valores $k$ pode levar à sobrerejeição da hipótese nula nesse mesmo contexto. Os experimentos de BelaireFranch e Contreras (2004) confirmaram o apontamento de Wright (2000) que utilizar os testes de razão de variância com vários intervalos de agregação resulta em elevação das taxas de rejeição e, portanto, sofrem com distorções amostrais quando são aplicados sequencialmente vários valores de $k$. Devido a esse problema do procedimento sequencial, utilizam-se os testes de Chow e Denning (1993) e de Belaire-Franch e Contreras (2004) nas análises de eficiência dos mercados, os quais são versões múltiplas dos testes de razão de variância propostos por Lo e MacKinlay (1988) e Wright (2000), respectivamente.

Chow e Denning (1993) estendem a razão de variância proposta por Lo e MacKinlay (1988), cuja definição pode ser dada por

$V R(k)=\frac{\frac{1}{T k} \sum_{t=k}^{T q}\left[y_{t}+\ldots, y_{t-k+1}-k\left(\frac{1}{t} \sum_{t=1}^{T} y_{t}\right)\right]^{2}}{\frac{1}{T k} \sum_{t=k}^{T q}\left[y_{t}-\left(\frac{1}{t} \sum_{t=1}^{T} y_{t}\right)\right]^{2}}$

e as estatísticas sob suposições de homocedasticidade e heterocedasticidade, $M_{1}$ e $M_{2}$, respectivamente, por

$$
M_{1}(k)=[V R(k)-1]\left[\frac{2(2 k-1)(k-1)}{3 k T}\right]^{-1 / 2}
$$


e

$$
M_{2}(k)=\frac{V R(k)-1}{\left[\sum_{j=1}^{k-1}\left[\frac{2(k-j)}{k}\right]^{2}\left\{\frac{\sum_{t=j+1}^{T}\left[y_{t}-\left(\frac{1}{t} \sum_{t=1}^{T} y_{t}\right)\right]^{2}\left[y_{t-j}-\left(\frac{1}{t} \sum_{t=1}^{T} y_{t}\right)\right]^{2}}{\left\{\sum_{t=1}^{T}\left[y_{t}-\left(\frac{1}{t} \sum_{t=1}^{T} y_{t}\right)\right]^{2}\right\}^{2}}\right\}\right.} .
$$

Esses testes utilizam-se do fato que, se os retornos são independentes e identicamente distribuídos, então, a variância do retorno no período $k$ é $k$ vezes a variância do retorno no primeiro período. Portanto, essas estatísticas devem ser próximas a 1 se $y_{t}$ for independente e identicamente distribuído (WRIGHT, 2000).

Segundo Belaire-Franch e Contreras (2004), o teste de Chow e Denning (1993) provê um procedimento para comparação múltipla de um conjunto de estimações de razão de variância. Para um conjunto de estatísticas $m$, a hipótese martingal é rejeitada se qualquer uma das razões de variância estimadas for estatisticamente significativa diferente de um. Assim, somente o valor absoluto máximo do conjunto de estatísticas é considerado. O teste de Chow e Denning (1993) tem como base que

$\operatorname{Pr}\left[\max \left(\left|M_{j}\left(k_{1}\right)\right|,\left|M_{j}\left(k_{2}\right)\right|, \ldots,\left|M_{j}\left(k_{m}\right)\right|\right) \leq\right.$ $\operatorname{SMM}(\alpha, m, T)] \geq 1-\alpha$

Disso, Chow e Denning (1993) sugerem comparar as estatísticas máximas $M_{1}$ ou $M_{2}$, em valores absolutos, com o valor crítico assintótico $\alpha$ do módulo máximo studentizado, MMS $(\alpha ; m ; 1)$, tal que $m$ é o número de defasagens $k$ (BELAIREFRANCH e CONTRERAS, 2004).

Wright (2000) propôs as estatísticas $R_{1}$ e $R_{2}$ para as $T$ observações das primeiras diferenças de $\left\{y_{1}, \ldots, y_{T}\right\}$, definidas como $^{7}$ :

7. As notações das fórmulas (6-11) seguem o trabalho de Belaire-Franch e Contreras (2004), pois, segundo os autores, houve erro tipográfico reconhecido por Wright em seu estudo publicado em Wright (2000).

$$
\begin{aligned}
& R_{1}(k)=\left(\frac{\frac{1}{T k} \sum_{t=k}^{T}\left(r_{1 t}+\ldots+r_{1 t-k+1}\right)^{2}}{\frac{1}{T} \sum_{t=1}^{T} r_{1 t}^{2}}-1\right) \times \phi(k)^{-\frac{1}{2},} \\
& R_{2}(k)=\left(\frac{\frac{1}{T k} \sum_{t=k}^{T}\left(r_{2 t}+\ldots+r_{2 t-k+1}\right)^{2}}{\frac{1}{T} \sum_{t=1}^{T} r_{2 t}^{2}}-1\right) \times \phi(k)^{-\frac{1}{2},}
\end{aligned}
$$

tal que

$$
\begin{aligned}
& r_{1 t}=\frac{r\left(y_{t}\right)-\frac{T+1}{2}}{\sqrt{\frac{(T-1)(T+1)}{12}}}, \\
& r_{2 t}=\Phi^{-1}\left(\frac{r\left(y_{t}\right)}{T+1}\right), \\
& \phi(k)=\frac{2(2 k-1)(k-1)}{3 k T},
\end{aligned}
$$

$r\left(y_{t}\right)$ é o posto entre $y_{1}, \ldots, y_{T}$ e $\Phi^{-1}$ a inversa da função de distribuição acumulada de uma normal. $\mathrm{O}$ teste com base nos sinais das primeiras diferenças é dado por

$S_{1}(k)=\left(\frac{\frac{1}{T k} \sum_{t=k}^{T}\left(s_{t}+\ldots+s_{t-k+1}\right)^{2}}{\frac{1}{T} \sum_{t=1}^{T} s_{t}^{2}}-1\right) \times \phi(k)^{-\frac{1}{2}}$,

tal que $s_{t}=2 u\left(y_{t}, 0\right), s_{t}(\bar{\mu})=2 u\left(y_{t}, \bar{\mu}\right) \mathrm{e}$

$$
u\left(x_{t}, q\right)=\left\{\begin{array}{c}
0,5 \quad \text { se } x_{t} \geq q \\
-0,5 \text { caso contrário }
\end{array}\right.
$$


Belaire-Franch e Contreras (2004) estendem os testes de sinais e de posto propostos por Wright (2000) para o contexto de razões de variância múltiplas. O procedimento adotado por esses autores foi adaptá-los ao contexto sugerido por Chow e Denning (1993). Assim, definem os seguintes testes com base na abordagem da estatística extrema de Chow e Denning (1993): Sob a suposição de primeiras diferenças independentes e identicamente distribuídas em Wright (2000), os testes $C D\left(R_{j}\right)$ seguem uma distribuição

$$
\max \left\{\left|R_{j}^{*}\left(k_{1}\right)\right|,\left|R_{j}^{*}\left(k_{2}\right)\right|, \ldots,\left|R_{j}^{*}\left(k_{m}\right)\right|\right\}
$$

tal que $R_{j}^{*}\left(k_{1}\right)$ é o teste com base no posto com quaisquer permutações aleatórias dos elementos $\{1,2, \ldots, T\}$. Sob a suposição de sequência de diferenças martingal em Wright (2000), os testes $C D\left(S_{j}\right)$ seguem uma distribuição

$$
\max \left\{\left|S_{j}^{*}\left(k_{1}\right)\right|,\left|S_{j}^{*}\left(k_{2}\right)\right|, \ldots,\left|S_{j}^{*}\left(k_{m}\right)\right|\right\}
$$

tal que $S_{j}^{*}\left(k_{1}\right)$ é o teste com base no posto calculado com uma sequência independente e identicamente distribuída $\left\{s_{t}^{*}\right\}_{t=1}^{T}$ em que cada elemento assume um com probabilidade $1 / 2$ e -1 caso contrário.

\subsection{Agrupamentos de séries temporais}

A finalidade da análise de agrupamentos de eficiência é identificar a estrutura do conjunto dos mercados futuros, organizando-os de forma homogênea quanto ao grau de eficiência de seus mercados. De acordo com Duda et al. (2001), inicia-se a investigação dos clusters definindo uma função de distância adequada para calcular a matriz de distâncias entre todos os pares amostrais. Além disso, é fundamental obter uma mensuração relevante das similaridades entre cada par de séries temporais na análise de cluster (BASTOS e CAIADO, 2014). Pois, se a distância for uma boa mensuração das dissimilaridades, então, espera-se que a distância entre as amostras de um mesmo cluster seja significativamente menor do que a distância amostral em diferentes clusters (DUDA et al., 2001).
Utiliza-se a métrica proposta por Bastos e Caiado (2014), que mensura a distância Euclidiana entre os vetores das estatísticas de razão de variância múltiplas, propostas por Chow e Denning (1993) e Belaire-Franch e Contreras (2004): $M_{1}$, $M_{2}, R_{1}, R_{2}$ e $S_{1}$. Esses vetores incluem as razões de variância estimadas por $k$ defasagens com a finalidade de identificar a dependência serial dos retornos.

Conforme ressaltam Duda et al. (2001), os resultados na análise de clusters dependem da escolha da distância (Euclidiana) como mensuração da dissimilaridade. Note que clusters formados por distância Euclidiana não são invariantes a transformações lineares ou outras transformações que distorçam a relação de distância. Assim, uma das formas para obter a invariância é normalizar os dados antes de formar os clusters, transformando todas as observações para que tenham média zero e variância unitária. Assim, para eliminar qualquer viés devido às diferentes escalas das variáveis, procede-se a estandardização das razões de variância antes de computar as distâncias (BASTOS e CAIADO, 2014).

Para exemplificar a métrica de Bastos e Caiado (2014), denote $v_{x}^{\prime}=\left[V R_{1 x}, V R_{2 x}, \ldots, V R_{p x}\right]$ e $v_{y}^{\prime}=\left[V R_{1 y}, V R_{2 y}, \ldots, V R_{p y}\right]$ como os vetores de dimensão $p$ das razões de variância estandardizadas para as séries temporais $x$ e $y$, respectivamente. A mensuração proposta por Bastos e Caiado (2014) entre esses vetores é

$$
d_{V R}(x, y)=\sqrt{\sum_{j=1}^{p}\left(V R_{j x}-V R_{j y}\right)^{2}} .
$$

Seja $n$ o número de séries temporais, computa-se a dissimilaridade entre cada par de séries, cujo resultado é a matriz de distância Euclidiana $D$ com $n(n-1) / 2$ diferentes pares de séries temporais.

Uma das soluções encontradas para análise de clusters em séries temporais é converter essas séries em dados estáticos para que sejam utilizados os algoritmos de clusters estáticos de forma direta (LIAO, 2005). Assim, pode-se considerar que a proposta de Bastos e Caiado (2014) segue essa abordagem pois diminui a dimensão 
dos dados, convertendo-os em um vetor com as características das séries, o que, segundo Liao (2005), permite aplicar os algoritmos tradicionais de clusters como o escalonamento multidimensional e a análise de cluster hierárquica por complete linkage.

\subsubsection{Análise de cluster hierárquica}

A homogeneidade dos grupos na análise de cluster permite que as similaridades das variáveis dentro de cada grupo sejam minimizadas e as dissimilaridades entre grupos sejam maximizadas (LIAO, 2005). Portanto, ao fazer uso da métrica de Bastos e Caiado (2014), evidenciam-se clusters de eficiência nos mercados futuros, dadas as características de dependência serial às séries. Segundo Bastos e Caiado (2014), o algoritmo mais comum na análise de cluster baseia-se na classificação hierárquica, sendo utilizado pelos autores em suas análises de aglomerações de eficiência.

Ao serem feitos os agrupamentos hierárquicos, os dados são organizados em uma estrutura hierárquica de acordo com a matriz de proximidade que pode ser representada em forma de dendogramas. O nó principal do dendrograma representa todo o conjunto de dados e os demais nós cada um dos dados. Os nós intermediários representam a distância entre os clusters e a altura do dendograma expressa a distância de cada par de clusters (XU e WUNSCH, 2005). De forma geral, a exemplificação desses procedimentos segundo o autor segue: a) começar com um cluster único $N$ e calcular a matriz de proximidade para os $N$ clusters; b) procurar a distância mínima $D\left(C_{i}, C_{j}\right)=\min _{1 \leq m, \leq N ; m \neq 1} D\left(C_{m}, C_{l}\right)$ tal que $D\left({ }^{*},{ }^{*}\right)$ é a métrica escolhida para a matriz de proximidade e, então, combinar o cluster $C_{i}$ e $C_{j}$ para formar um novo cluster; c) atualizar a matriz de proximidade ao calcular as distâncias entre o novo cluster e os demais; d) repetir os passos 2 e 3 até que todos os objetos estejam no mesmo cluster.

Assim como em Bastos e Caiado (2014), escolhe-se o algoritmo complete linkage para formação dos agrupamentos hierárquicos. Segundo Xu e Wunsch (2005), esse método é realizado com base na distância máxima dos pares de objetos para definir a distância dos clusters internos e pode ser definido por $D\left(C_{l},\left(C_{i}, C_{j}\right)\right)=\max \left(D\left(C_{l}, C_{j}\right), D\left(C_{l}, C_{j}\right)\right)$.

Para avaliar a validade dos clusters formados, utiliza-se o procedimento de Suzuki e Shimodaira (2006). Nesse procedimento, para cada cluster no dendograma, calculam-se os valores- $p$ aproximadamente não enviesados por multiscale bootstrap de Shimodaira (2002). Esses valores- $p$ representam a possibilidade de que o cluster em análise seja um cluster verdadeiro.

\subsection{Base de dados}

A base de dados $^{8}$ foi composta pelos retornos dos contratos dispostos na Tabela 2. Esses contratos foram obtidos no terminal Bloomberg, disponibilizados como contratos contínuos e equivalem ao primeiro vencimento. A seleção desses contratos e, consequentemente, das bolsas e dos países, foi procedida com base na listagem de todos os contratos futuros disponíveis para negociação nas bolsas do mundo, à época de execução do presente estudo, disponibilizada pela Future Industry Association (FIA). Dessa listagem, que tem a quantidade de contratos negociados agregada de todos os vencimentos, foram selecionados todos os contratos em que houve negociações do complexo soja: soja, farelo de soja e óleo de soja.

8. Deve-se destacar que não foram procedidos ajustes na base de dados de retornos, tais como deflacionamento, padronização de moedas de negociação e de quantidade de observações por interpolação, assim como Bastos e Caiado (2014). Justifica-se essa escolha devido à possível alteração do conjunto informacional presente nos preços históricos e, portanto, proporcionaria provável distorção nas séries, afetando os testes quanto à previsibilidade e, por conseguinte, as inferências sobre a eficiência fraca de cada mercado. Tais informações, além dos preços históricos, não têm aderência com o arcabouço testável à eficiência informacional utilizada, qual seja: hipótese fraca de eficiência de mercado. 
Tabela 2. Base de dados

\begin{tabular}{ccccccc}
\hline \multicolumn{1}{c}{ Contrato } & Bolsa & País & Contratos negociados & Código Bloomberg & Início amostral & Final amostral \\
\hline \multirow{6}{*}{ Soja } & BVMF & Brasil & 136.544 & IFS & $02-2011$ & $12-2013$ \\
& CBT & Estados Unidos & 143.906 .451 & S & $02-2011$ & $12-2013$ \\
& DCE & China & 81.708 .457 & AK & $02-2011$ & $12-2013$ \\
& MTB & Argentina & 445.442 & VT & $02-2011$ & $12-2013$ \\
& NCD & Índia & 16.098 .420 & Q8 & $02-2011$ & $12-2013$ \\
& SAF & África do Sul & 947.893 & SY & $02-2011$ & $12-2013$ \\
\multirow{2}{*}{ Farelo de Soja } & TKT & Japão & 2.059 .029 & JS & $02-2011$ & $12-2013$ \\
\hline \multirow{2}{*}{ Óleo de Soja } & DCT & Estados Unidos & 55.344 .808 & SM & $02-2011$ & $12-2013$ \\
& CBT & Estados Unidos & 75.590 .011 & AE & $02-2011$ & $12-2013$ \\
\hline & DCE & China & 223.205 .777 & BO & $02-2011$ & $12-2013$ \\
& NCD & Índia & 18.443 .920 & SH & $02-2011$ & $12-2013$ \\
\hline
\end{tabular}

Nota: Bolsa de Valores, Mercadorias e Futuros (BVMF), Chicago Board of Trade (CBT), Dalian Commodity Exchange (DCE), Mercado a Término de Rosario (ROFX), National Commodities and Derivatives Exchange (NCD), South African Futures Exchange (SAF) e Tokyo Commodity Exchange (TKT) - conforme ISO 10383 - Market Identifier Code. A coluna contratos negociados se refere a quantidade total de contratos negociados no período de 2011 a 2013, para todos os vencimentos, e foi obtida junto a Futures Industry Association (FIA).

Fonte: Bloomberg e Futures Industry Association (FIA).

Escolheu-se o primeiro vencimento devido ao maior volume negocial nesses contratos. Segundo Kellard et al. (1999), a escolha do contrato mais próximo do vencimento auxilia a minimizar as ineficiências devido ao prêmio de risco e aos erros de aprendizado. Ademais, Kumar e Pandey (2013) ressaltaram que, nos mercados futuros de commodities de seu estudo, há maior volume negocial no primeiro vencimento, sendo que nos demais contratos próximos a vencer existe necessidade de elevar a participação dos agentes, o que indica que os hedgers e especuladores devem utilizar o contrato mais próximo do vencimento.

Nota-se discrepância de liquidez entre os ativos em análise, medida pela quantidade de contratos negociados entre o período de 2011 a $2013^{9}$. Os contratos com maior liquidez foram os negociados na bolsa americana (CBT) e na chinesa (DCE), sendo que essa elevada liquidez pode propiciar retornos condizentes com uma sequência de diferença martingal. Entretanto, influência

9. Dos contratos em análise, todos permanecem com volume negocial sem variações abruptas. Para 2015, exceções foram os contratos de soja negociados na bolsa brasileira (4.598) e na bolsa japonesa, que houve redução para (159.602). Ademais, na bolsa sul-africana, houve lançamento de um novo contrato, mas com volume similar ao anterior. oposta pode ser indicada para os contratos negociados nas demais bolsas, nas quais ocorrem pouca quantidade negocial e, portanto, refletindo em possível previsibilidade.

Devido à inexistência de séries temporais longas para os mercados emergentes e recentes lançamentos contratuais, optou-se pelo início das séries em fevereiro de 2011. Esse início amostral se deve ao recente lançamento dos contratos de soja na BVMF. Assim, possibilita a análise do maior número de contratos do complexo soja nas diferentes bolsas.

\section{Resultados e discussões}

O requisito básico de qualquer análise estatística dos mercados é a existência de algumas propriedades estatísticas (CONT, 2001). Algumas dessas propriedades, tidas como fatos estilizados de séries temporais financeiras e apresentadas por Cont (2001), não são confirmadas em todos os mercados futuros analisados. Existem discrepâncias a esses fatos nas seguintes características: ausência de autocorrelação e cluster de volatilidade. Por outro lado, confirmam-se características para todos os mercados, com respeito a: caudas pesadas e estacionariedade. Assim, apresentam- 
-se a seguir essas características às séries de retornos dos contratos futuros de soja, assim como de seus derivados: farelo e óleo. Primeiramente, analisam-se as estatísticas descritivas. E, por conseguinte, as estatísticas de raiz unitária, autocorrelação e heterocedasticidade. Concluindo, a análise de sequência martingal com os testes de razão de variância, assim como a análise de clusters de eficiência.

Devido às características de cada mercado, houve diferenças na quantidade de observações. ${ }^{10} \mathrm{O}$ contrato com maior número de dias de negociação foi o de soja, negociado na bolsa indiana de futuros (NCD), enquanto que a menor quantidade de observações ocorreu no contrato de soja, negociado no Japão (TKT). Essa discrepância no número de observações se deve aos feriados, assim como aos períodos de não negociação dos contratos, os quais diferem nas bolsas. Note que, apesar disso, a quantidade de observações é grande o suficiente para o procedimento metodológico e análise de eficiência empregados neste estudo. Pois, conforme simulações de Belaire-Franch e Contreras (2004) e Chow e Denning (1993), não houve distorções amostrais para a quantidade de observações às séries dispostas na Tabela 3.

Observa-se a existência de valores extremos nas séries, negativos e positivos, indicadas pelos mínimos e máximos. Podem-se exemplificar esses casos extremos nas variações percentuais negativas diárias para: a soja negociada na bolsa indiana NCD (-19\%) e, também, para a soja negociada na BVMF (-17\%). Por outro lado, variações positivas extremas podem ser exemplificadas na soja negociada na bolsa japonesa TKT (+37\%), assim

10. Ao serem procedidos os testes de razão de variância em cada série temporal, mesmo havendo quantidade observacional diferente entre elas, permite-se o do método em análise, uma vez que essas séries são convertidas em dados estáticos pela métrica proposta por Bastos e Caiado (2014). Vale ressaltar que, devido às ocorrências de períodos sem negociação, Bastos e Caiado (2014) também utilizaram séries temporais com quantidade de observações diferentes suas demonstrações empíricas. Os autores excluíram as observações repetidas das séries originais, sendo que essas estavam presentes nos dias em que não houve negociações. como no farelo de soja negociado na bolsa americana CBT (+17\%). Na visão de Garcia e Leuthold (2004), essas ocorrências podem ser explicadas, por exemplo, devido ao efeito vencimento, como também à microestrutura característica dos mercados: volume; composição e quantidade dos agentes atuantes nos mercados. Ademais, essas variações diárias abruptas refletem nas medidas de assimetria e sugerem um possível comportamento não normal às séries.

As maiores volatilidades ocorreram nos mercados de soja, farelo de soja e óleo de soja, negociados nas bolsas TKT, CBT e DCE, respectivamente. Destaca-se o mercado da soja negociado na DCE como o menos volátil. Essas evidências de variâncias díspares são consistentes com os argumentos de Garcia e Leuthold (2004) de que as volatilidades são influenciadas pelos mercados à vista, cujas informações são transmitidas aos preços em importantes períodos. Exemplificam esses períodos coincidentes com as volatilidades em uma boa safra, mas, também, por outro lado, os períodos de estoque escasso.

Conforme advoga a lei do preço único, os preços de um mesmo produto, no caso, a soja, negociada em diferentes lugares, devem ser iguais, descontados os custos de transação. Disso, espera-se que as distribuições empíricas dos retornos desses mercados sejam similares. No entanto, conforme os sinais dos coeficientes de assimetria nos mercados de soja, farelo de soja e óleo de soja, isso não se verifica. Ocorrem, por exemplo, discrepâncias nas variações dos mercados de soja na DCE e na TKT, comparando-os aos demais. Verifica-se, também, dissimilaridade entre os mercados de farelo de soja (CBT vs. DCE) e entre os mercados de óleo de soja na (DCE vs. NCD). Uma vez que esses contratos não são negociados na mesma moeda, além de possuírem diferentes horários de negociação, as variações cambiais, bem como a assincronia desses horários, podem ser consideradas como possíveis fatores explicativos para essas evidências.

Os mercados emergentes são caracterizados por distribuições não normais (KUMAR e PANDEY, 2013). Isso se verifica por meio do teste Jarque-Bera (Tabela 3). Além desses mercados, 
Tabela 3. Estatísticas descritivas

\begin{tabular}{|c|c|c|c|c|c|c|c|}
\hline & \multicolumn{7}{|c|}{ Soja } \\
\hline & $B V M F$ & $C B T$ & $D C E$ & MTB & $N C D$ & $S A F$ & TKT \\
\hline Observações & 709 & 731 & 704 & 675 & 869 & 690 & 546 \\
\hline Mínimo & $-0,172$ & $-0,0991$ & $-0,0571$ & $-0,1305$ & $-0,1991$ & $-0,1192$ & $-0,1292$ \\
\hline Máximo & 0,0514 & 0,0481 & 0,0583 & 0,0411 & 0,0681 & 0,05 & 0,3778 \\
\hline Média & $1 \times 10^{-4}$ & $-1 \times 10^{-4}$ & $1 \times 10^{-4}$ & $-1 \times 10^{-4}$ & $5 \times 10^{-4}$ & $7 \times 10^{-4}$ & $6 \times 10^{-4}$ \\
\hline Variância & $2 \times 10^{-4}$ & $2 \times 10^{-4}$ & $1 \times 10^{-4}$ & $1 \times 10^{-4}$ & $3 \times 10^{-4}$ & $2 \times 10^{-4}$ & $9 \times 10^{-4}$ \\
\hline Assimetria & $-3,8641$ & $-0,8927$ & 0,875 & $-2,0293$ & $-2,6188$ & $-1,6222$ & 4,5869 \\
\hline Curtose & 44,2913 & 7,6187 & 16,1449 & 24,2418 & 35,2113 & 14,1051 & 56,485 \\
\hline \multirow[t]{3}{*}{ Jarque-Bera } & $52132,0802^{\mathrm{a}}$ & $746,84^{\mathrm{a}}$ & 5158,2563 & $13153,6975^{\mathrm{a}}$ & $38561,9715^{a}$ & $3848,1847^{a}$ & $66994,2666^{a}$ \\
\hline & \multicolumn{2}{|c|}{ Farelo de Soja } & \multicolumn{3}{|c|}{ Óleo de Soja } & & \\
\hline & $C B T$ & $D C E$ & CBT & $D C E$ & $N C D$ & & \\
\hline Observações & 731 & 704 & 732 & 704 & 882 & & \\
\hline Mínimo & $-0,1706$ & $-0,0728$ & $-0,0453$ & $-0,0619$ & $-0,1047$ & & \\
\hline Máximo & 0,057 & 0,1601 & 0,042 & 0,1231 & 0,0372 & & \\
\hline Média & $2 \times 10^{-4}$ & $1 \times 10^{-4}$ & $-6 \times 10^{-4}$ & $-5 \times 10^{-4}$ & $1 \times 10^{-4}$ & & \\
\hline Variância & $4 \times 10^{-4}$ & $2 \times 10^{-4}$ & $1 \times 10^{-4}$ & $2 \times 10^{-4}$ & $1 \times 10^{-4}$ & & \\
\hline Assimetria & $-1,7578$ & 1,1556 & 0,1051 & 1,0606 & $-1,5711$ & & \\
\hline Curtose & 16,3986 & 26,3255 & 3,8367 & 23,0427 & 16,4768 & & \\
\hline Jarque-Bera & $5844,3663^{a}$ & $16116,3503^{a}$ & $22,7021^{\mathrm{a}}$ & $11915,447^{a}$ & $7037,5566^{a}$ & & \\
\hline
\end{tabular}

Nota: a, b e c representam significância estatística a 1\%, 5\% e 10\%, respectivamente. Bolsa de Valores, Mercadorias e Futuros (BVMF), Chicago Board of Trade (CBT), Dalian Commodity Exchange (DCE), Mercado a Término de Buenos Aires (MTB), National Commodities and Derivatives Exchange (NCD), South African Futures Exchange (SAF) e Tokyo Commodity Exchange (TKT) - conforme ISO 10383 - Market Identifier Code.

Tabela 4. Estatísticas de raiz unitária, autocorrelação e heterocedasticidade

\begin{tabular}{|c|c|c|c|c|c|c|c|}
\hline & \multicolumn{7}{|c|}{ Soja } \\
\hline & $B V M F$ & $C B T$ & $D C E$ & MTB & $N C D$ & $S A F$ & TKT \\
\hline DF-GLS MAIC & $-8,184_{7}$ & $-6,096_{10}$ & $-8,237_{8}$ & $-3,173_{10}$ & $-8,163_{8}$ & $-7,299_{9}$ & $-22,474_{0}$ \\
\hline Ljung-Box ponderado $\left(\tilde{Q}_{w}\right)$ & 3,192 & $7,666^{c}$ & 6,847 & $7,624^{c}$ & $9,068^{\mathrm{b}}$ & $40,562^{\mathrm{a}}$ & 5,754 \\
\hline Monti ponderado $\left(\tilde{M}_{W}\right)$ & 2,996 & $8,303^{c}$ & 7,077 & $7,688^{c}$ & $8,569^{\mathrm{b}}$ & $38,189^{a}$ & 5,806 \\
\hline Ljung-Box ponderado $\left(\tilde{Q}_{w}^{*}\right)$ & 0,088 & 5,156 & $15,607^{a}$ & 0,418 & 0,740 & $81,155^{\mathrm{a}}$ & 2,268 \\
\hline \multirow[t]{3}{*}{ Monti ponderado $\left(\tilde{M}_{\mathrm{W}}^{*}\right)$} & 0,088 & 4,935 & $16,366^{a}$ & 0,426 & 0,746 & $86,248^{\mathrm{a}}$ & 2,277 \\
\hline & \multicolumn{2}{|c|}{ Farelo de Soja } & \multicolumn{3}{|c|}{ Óleo de Soja } & & \\
\hline & $C B T$ & $D C E$ & $C B T$ & $D C E$ & NCD & & \\
\hline DF-GLS MAIC & $-5,73_{10}$ & $-7,899_{8}$ & $-6,088_{10}$ & $-18,002_{1}$ & $-6,323_{8}$ & & \\
\hline Ljung-Box ponderado $\left(\tilde{Q}_{w}\right)$ & 2,707 & 3,260 & 6,199 & 2,635 & 5,218 & & \\
\hline Monti ponderado $\left(\tilde{M}_{W}\right)$ & 2,739 & 3,348 & 6,014 & 2,591 & 5,134 & & \\
\hline Ljung-Box ponderado $\left(\tilde{Q}_{w}^{*}\right)$ & 2,613 & $9,816^{\mathrm{b}}$ & 15,454 & 0,548 & $14,234^{\mathrm{a}}$ & & \\
\hline Monti ponderado $\left(\tilde{M}_{w}^{*}\right)$ & 2,622 & $10,17^{\mathrm{b}}$ & $12,696^{\mathrm{a}}$ & 0,566 & $12,894^{\mathrm{a}}$ & & \\
\hline
\end{tabular}

Nota: a, b e c representam significância estatística a 1\%, 5\% e 10\%, respectivamente. Bolsa de Valores, Mercadorias e Futuros (BVMF), Chicago Board of Trade (CBT), Dalian Commodity Exchange (DCE), Mercado a Término de Buenos Aires (MTB), National Commodities and Derivatives Exchange (NCD), South African Futures Exchange (SAF) e Tokyo Commodity Exchange (TKT) - conforme ISO 10383 - Market Identifier Code. Os números subscritos no teste DF-GLS denotam os lags do critério informacional Akaike modificado. Os valores críticos desse teste são: $-3,42,-2,91$ e $-2,62$, a $1 \%, 5 \%$ e 10\%, respectivamente. Box-Pierce ponderado e Ljung-Box ponderados denotam as estatísticas propostas por Fisher e Gallagher (2012). Os sobrescritos * denotam essas estatísticas com base nos resíduos ao quadrado. 
os tidos como desenvolvidos - negociados na CBT - também podem ser caracterizados pela não normalidade dos retornos. Para a análise de eficiência, essas evidências de não normalidade às séries de retornos, indicadas pelos coeficientes de assimetria, curtose e pelo teste de JarqueBera, corroboram a escolha da versão múltipla ao teste de Wright (2000). Pois, com base nos argumentos de Belaire-Franch e Contreras (2004), a ocorrência de caudas pesadas pode provocar distorções nas razões de variância. Ademais, Wright (2000) ressalta que seu teste tem maior poder do que os testes anteriores para o caso de dados não normais.

Dentre os requisitos básicos destacados por Cont (2001) para a análise de dados desses mercados, deve-se considerar a invariância do processo de retorno no tempo: hipótese de estacionariedade. Conforme se espera, os retornos apresentam-se estacionários. Estas evidências sugeridas pela significância estatística dos testes DF-GLS, com o critério informacional de Akaike modificado roboram o fato estilizado ressaltado por Cont (2001). Resultados similares a esses foram encontrados nos estudos dos mercados futuros de soja revistos na Tabela 1. Os preços não sendo estacionários, conforme esperado, confirma a preferência ao uso dos retornos no presente estudo. Assim, conforme Escanciano e Lobato (2009b), descarta-se o uso da hipótese de sequência martingal dos preços. E, consequentemente, utiliza-se a hipótese de sequência de diferença martingal dos retornos. Conclui-se, portanto, a adequabilidade da hipótese de sequência de diferenças martingal para verificar a eficiência fraca desses mercados.

Em relação ao fato estilizado de autocorrelação linear inexistente, destacam-se todos os mercados derivados da soja (farelo e óleo) como evidências favoráveis a este fato. A autocorrelação linear, ressaltada por Cont (2001) como sendo insignificante, exceto para dados de alta frequência, os quais ocorrem devido aos efeitos da microestrutura, não se confirma nos mercados não derivados. Apesar de ser reconhecido que os movimentos nos preços de mercados líquidos não exibem quaisquer autocorrelações significantes, conforme Cont (2001), há evidências de autocorrelação nos mercados de soja não derivados, quais sejam: CBT, MTB, NCD e SAF. Portanto, diante dessas evidências, não se confirma uma das implicações sugeridas por Ross (2004) para a eficiência fraca nesses quatro mercados: não correlação serial dos retornos.

As evidências de heterocedastícia nas séries futuras do complexo soja são discrepantes às encontradas normalmente em ativos financeiros. Conforme Wright (2000), existem fortes evidências de heterocedasticidade nos retornos de ativos financeiros, o que significa que os retornos não são independentes e identicamente distribuídos (i.i.d.). No entanto, evidenciou-se presença de heterocedasticidade apenas nos mercados de soja (DCE e SAF), assim como no de farelo de soja (DCE) e óleo de soja (CBT e NCD). Para verificar a presença de previsibilidade nessas séries, destaca-se, portanto, a necessidade de utilizar testes que sejam robustos à presença de heterocedasticidade. Nos demais mercados do complexo soja, as evidências contrárias aos ativos financeiros implicam, por exemplo, que as modelagens nesses mercados, nos períodos em análise, não devem ser realizadas com base em modelos de heterocedastícia condicional da família $\mathrm{ARCH}$, quais sejam: univariados ou multivariados.

Wright (2000) ressalta que as evidências sobre os retornos obedecerem a uma sequência de diferença martingal são inconclusivas. No entanto, é um importante questionamento, pois inúmeros modelos pressupõem que os retornos sigam uma sequência de diferença martingal. Assim sendo, verifica-se essa hipótese martingal com o uso dos testes dispostos nas Tabelas 5 e 6 .

De acordo com as evidências de heterocedasticidade reportadas na Tabela 4, devem-se considerar as estatísticas CD2 - robustas a essa evidência - nos seguintes mercados: soja (DCE e SAF), farelo de soja (DCE) e óleo de soja (CBT e NCD). Uma vez que para que os retornos sejam independentes e identicamente distribuídos, a variância dos $k$-períodos deve ser $k$ vezes a variância de um período (WRIGHT, 2000). Essa pro- 
Tabela 5. Estatísticas Chow e Denning (1993)

\begin{tabular}{|c|c|c|c|c|c|c|c|}
\hline & \multicolumn{7}{|c|}{ Soja } \\
\hline & $B V M F$ & CBT & $D C E$ & MTB & NCD & SAF & TKT \\
\hline Estatística CD1 & 1,988 & 1,154 & 1,936 & $2,401^{c}$ & $2,612^{b}$ & $6,001^{a}$ & 1,012 \\
\hline \multirow[t]{3}{*}{ Estatística CD2 } & 2,067 & 0,985 & 1,36 & 1,98 & $2,401^{c}$ & $3,166^{a}$ & 0,7 \\
\hline & \multicolumn{2}{|c|}{ Farelo de Soja } & \multicolumn{3}{|c|}{ Óleo de Soja } & & \\
\hline & $C B T$ & $D C E$ & $C B T$ & $D C E$ & NCD & & \\
\hline Estatística CD1 & 0,83 & 0,718 & 1,041 & 1,6 & 2,004 & & \\
\hline Estatística CD2 & 0,74 & 0,383 & 0,975 & 1,599 & 1,49 & & \\
\hline
\end{tabular}

Nota: a, b e c representam significância estatística a 1\%, 5\% e 10\%, respectivamente. Bolsa de Valores, Mercadorias e Futuros (BVMF), Chicago Board of Trade (CBT), Dalian Commodity Exchange (DCE), Mercado a Término de Buenos Aires (MTB), National Commodities and Derivatives Exchange (NCD), South African Futures Exchange (SAF) e Tokyo Commodity Exchange (TKT) - conforme ISO 10383 - Market Identifier Code.

Fonte: Dados da pesquisa.

Tabela 6. Estatísticas Belaire-Franch e Contreras (2004)

\begin{tabular}{|c|c|c|c|c|c|c|c|}
\hline & & & & Soja & & & \\
\hline & $B V M F$ & CBT & $D C E$ & MTB & $N C D$ & SAF & TKT \\
\hline Estatística JR1 & $2,639^{b}$ & 0,787 & 1,444 & 1,984 & $2,417^{b}$ & $5,010^{a}$ & $2,737^{b}$ \\
\hline Estatística JR2 & $2,770^{\mathrm{b}}$ & 1,199 & 0,777 & $2,224^{c}$ & $2,685^{\mathrm{b}}$ & $4,782^{\mathrm{a}}$ & $2,311^{\mathrm{b}}$ \\
\hline \multirow[t]{3}{*}{ Estatística JS1 } & 1,792 & 0,729 & $5,108^{\mathrm{a}}$ & $2,141^{c}$ & 1,833 & $3,600^{\mathrm{a}}$ & $3,057^{\circ}$ \\
\hline & \multicolumn{2}{|c|}{ Farelo de Soja } & \multicolumn{3}{|c|}{ Óleo de Soja } & & \\
\hline & $C B T$ & $D C E$ & $C B T$ & $D C E$ & $N C D$ & & \\
\hline Estatística JR1 & 0,982 & $2,999^{a}$ & 1,413 & 1,441 & 0,943 & & \\
\hline Estatística JR2 & 1,306 & $2,699^{b}$ & 1,267 & 1,624 & 1,022 & & \\
\hline Estatística JS1 & 1,015 & $7,970^{\mathrm{a}}$ & 0,961 & $19,410^{\mathrm{a}}$ & 0,606 & & \\
\hline
\end{tabular}

Nota: a, b e c representam significância estatística a 1\%, 5\% e 10\%, respectivamente. Bolsa de Valores, Mercadorias e Futuros (BVMF), Chicago Board of Trade (CBT), Dalian Commodity Exchange (DCE), Mercado a Término de Buenos Aires (MTB), National Commodities and Derivatives Exchange (NCD), South African Futures Exchange (SAF) e Tokyo Commodity Exchange (TKT) - conforme ISO 10383 - Market Identifier Code.

Fonte: Dados da pesquisa.

priedade, explorada no teste de Chow e Denning (1993) aos retornos, não se mantém apenas nos mercados de soja da Argentina (MTB), da África do Sul (SAF) e da Índia (NCD). Assim, evidencia-se previsibilidade nesses mercados, por conseguinte, infere-se que sejam não eficientes na forma fraca. Nos demais mercados, pode-se inferir, por meio do teste de Chow e Denning (1993), que sejam eficientes.

Apresentam-se, na Tabela 6, as estatísticas propostas por Belaire-Franch e Contreras (2004) para analisar a hipótese de diferença martingal. Nota-se que os testes de razão de variância, com base no rank e nos sinais, tendem a rejeitar a hipótese de sequência de diferença martingal com maior frequência do que os realizados com o procedimento de Chow e Denning (1993). Isso é consistente com as evidências em simulações de
Monte Carlo realizadas tanto por Wright (2000) como por Belaire-Franch e Contreras (2004). Nessas simulações demonstraram que os testes de razão de variância possuem maior poder do que os testes convencionais, por exemplo, comparados ao teste de Chow e Denning (1993). Uma vez que foi evidenciada a não normalidade dos retornos, de acordo com a Tabela 3, robora o uso dos testes múltiplos propostos por Belaire-Franch e Contreras (2004) para o teste de Wright (2000). Pois, segundo Wright (2000), seus testes propostos têm maior poder caso os dados possuam elevada não normalidade.

Ao comparar os resultados dos testes dispostos nas Tabelas 5 e 6, encontram-se evidências díspares entre esses testes, bem como comparando-os com a literatura discutida a partir da Tabela 1. Em relação à disparidade entre os testes, 
não devem ser consideradas como falta de poder destes. Pois, nas proposições de Chow e Denning (1993) e Belaire-Franch e Contreras (2004), suas simulações de Monte Carlo sugerem adequabilidade do tamanho amostral no presente estudo. Deve-se notar, também, que a adoção de vários testes pode resultar em sobredimensionamento, apesar do aumento do poder nesse procedimento.

Nota-se ausência de rejeição da hipótese nula em todos os testes apenas para os mercados futuros negociados na CBT e para o mercado futuro de óleo de soja negociado na NCD. Disso, depreende-se que os mercados futuros norte-americanos podem ser considerados como eficientes, assim como o mercado de óleo de soja da NCD. Comparando os resultados encontrados, tem-se que, para as evidências na CBT, os testes convergem para a conclusão de eficiência, assim como encontrado por Chinn e Coibion (2014), mas divergente a Kellard et al. (1999). Encontra-se divergência também em relação à evidência desfavorável reportada por Sahai (2014) no mercado de óleo de soja na NCD.

O oposto é evidenciado nos demais mercados: soja (BVMF, DCE, MTB, NCD, SAF e TKT), farelo e óleo de soja (DCE). Pode-se inferir que há previsibilidade e, portanto, não eficiência fraca nesses mercados.

Em relação aos contratos da BVMF, assim como Abitante (2008), houve resultados contraditórios, demonstrando resultados opostos entre os testes das Tabelas 5 e 6 . No entanto, devido à adequabilidade dos testes de Belaire-Franch e Contreras (2004) em dados não normais, as evidências de não eficiência corroboram os resultados de Fraga e Silva Neto (2011). Por outro lado, coaduna-se com os resultados desfavoráveis à eficiência de Pacheco (2004) no mercado MTB. Ressalta-se que não se evidenciou heterocedasticidade nesse mercado, o que permite inferir a adequação dos resultados com base nos testes não robustos a essas características.

Destaca-se essa adequabilidade também para as evidências opostas entre os testes nos mercados da DCE, NCD e TKT. Em particular, para os mercados de soja e óleo de soja (DCE), apenas os testes conjuntos com base nos sinais $\left(J S_{1}\right)$ evidenciaram não eficiência. Isso pode ser explicado pelas caudas pesadas das séries. Pois, segundo Wright (2000), os testes por sinais têm maior poder a caudas pesadas do que os tradicionais e com base no rank.

Nos mercados de soja (DCE, NCD e TKT), Wang e Ke (2005), Zheng e Wang (2013), Kumar e Pandey (2013) e Aruga (2011) compartilham evidências mistas à eficiência, quais sejam: discrepância entre a eficiência de curto e longo prazo. Assim, com base no resultado reportado na Tabela 6, confirma-se a falta de eficiência informacional. $\mathrm{O}$ mesmo pode-se inferir no mercado de óleo de soja (DCE), o qual também foi evidenciado como não eficiente por Peng, Yong e Suo (2006). Nota-se que não foram encontrados estudos para o mercado de soja (SAF), o que auxiliaria como efeito comparativo as mesmas inferências em todos os testes deste mercado: desfavoráveis à eficiência.

A melhoria na eficiência informacional dos mercados emergentes encontra respaldo em Kumar e Pandey (2013) e Zheng e Wang (2013), que sugerem mudanças institucionais nos mercados, atração de diversos agentes, o que, consequentemente, proporciona melhora informacional dos preços. Cabe ressaltar que o contrato futuro de soja da CBT é utilizado por produtores e tradings norte-americanas e também da América do Sul e demais continentes (ABITANTE, 2008). Assim sendo, justifica-se a formação desse cluster destacado pela área tracejada.

Com base nas estatísticas reportadas nas Tabelas 5 e 6, pode-se inferir a formação de um grupo de eficiência, composto por óleo de soja (NCD e CBT), farelo de soja (CBT) e soja (DCE e CBT). Em particular, destaca-se o aglomerado formado pelos mercados negociados na CBT. Rejeita-se a hipótese de não existência de cluster para os três mercados futuros de soja e seus derivados a 5\% de significância estatística. Isso significa que há um mesmo padrão de dependência linear nesses mercados e, por conseguinte, pode-se considerar que os mercados norte-americanos possuem similaridade na eficiência de seus mercados. 
Figura 1. Dendograma para a distância Euclidiana entre os contratos futuros do complexo soja

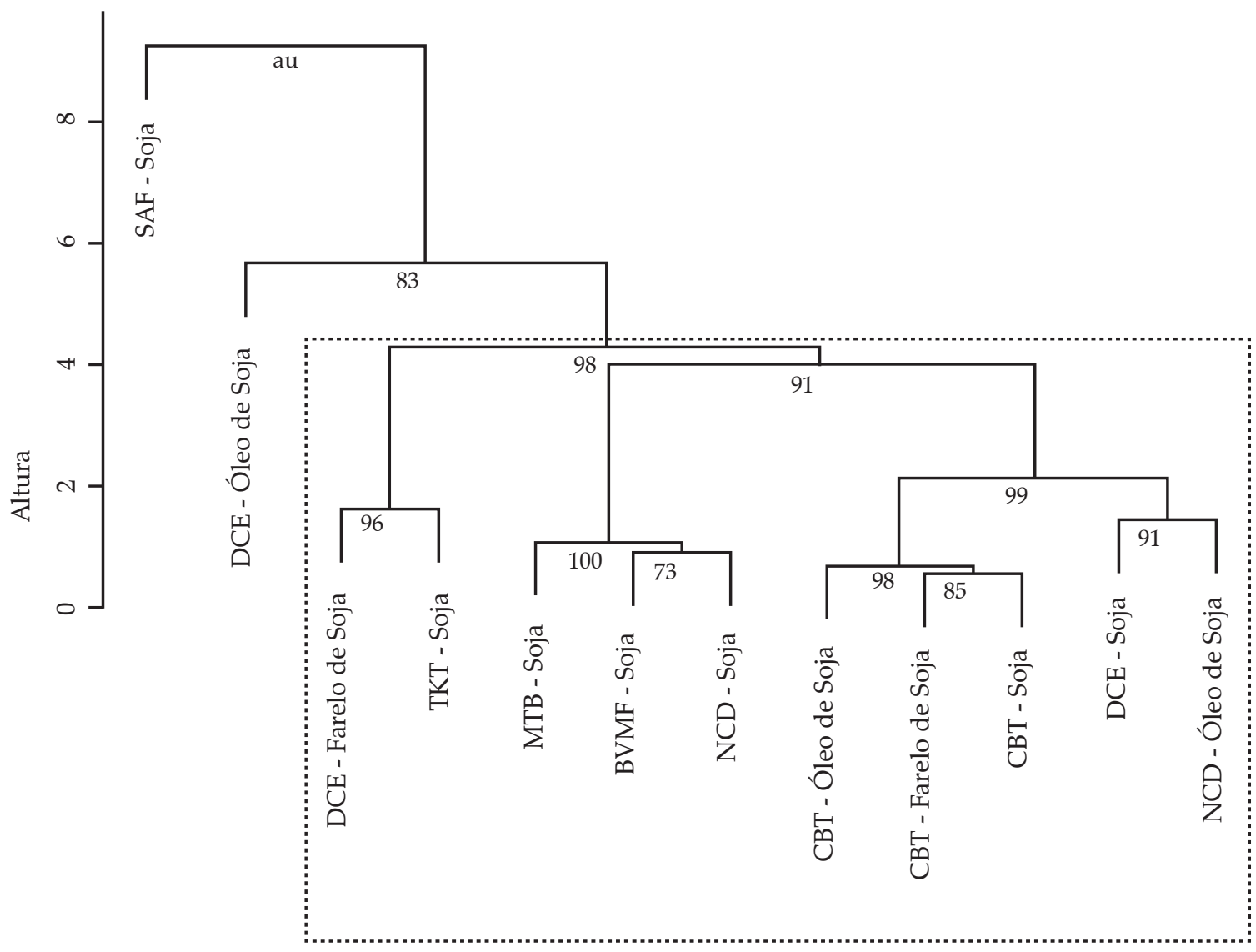

Nota: Os valores dispostos abaixo dos nós denotam os valores-p aproximadamente não enviesador por multiscale bootstrap de Shimodaira (2002), Shimodaira (2004). Bolsa de Valores, Mercadorias e Futuros (BVMF), Chicago Board of Trade (CBT), Dalian Commodity Exchange (DCE), Mercado a Término de Buenos Aires (MTB), National Commodities and Derivatives Exchange (NCD), South African Futures Exchange (SAF) e Tokyo Commodity Exchange (TKT) - conforme ISO 10383 - Market Identifier Code.

Fonte: Dados da pesquisa

Padrão semelhante a esse, dentro de uma mesma bolsa, não se verifica nas demais bolsas que ofertam derivados de soja: DCE e NCD. Isso sugere que o conteúdo informacional contido nos retornos, mesmo dentro de uma mesma bolsa, não se difunde entre os participantes da mesma forma, como se evidencia no mercado norte-americano (CBT).

Conforme argumentos de Wang e Ke (2005) e Zheng e Wang (2013), os resultados favoráveis à eficiência desses mercados possuem importantes implicações aos agentes, sejam eles locais ou internacionais. É de interesse dos agentes que importam, exportam, produzem, comercializam e processam essa commodity, uma vez que podem servir como mecanismo de hedge às suas transações. Assim sendo, as sinalizações contidas nesses mercados não podem ser ignoradas pelos agentes internacionais nas suas tomadas de decisões, os quais podem se valer dos contratos futuros na mitigação de riscos. Além disso, mercados eficientes podem auxiliar os governos, pesquisadores e investidores, fornecendo informações de preços críveis, bem como sinalizações essenciais aos policy makers.

Por outro lado, reportam-se dois agrupamentos que podem ser caracterizados como não eficientes, devido às rejeições das hipóteses nulas 
apresentadas nas Tabelas 5 e 6, quais sejam: a) soja (MTB, BVMF e NCD) e b) soja (TKT) e farelo de soja (DCE). Deve-se enfatizar que esse cluster de previsibilidade pode ser explicado por fatores estruturais comuns aos mercados de países emergentes: efeitos da pouca negociação de seus mercados, conforme demonstrado na Tabela 2, efeitos de assimetria de informações entre os participantes bem como das situações institucionais em desenvolvimento, as quais se fazem presentes. Fatores esses que devem exercer maior influência nos únicos mercados que não foram classificados como pertencentes a algum cluster: soja (SAF) e de óleo de soja (DCE).

Os resultados de Kumar e Pandey (2013) roboram o fato de que a baixa atividade negocial tem papel importante na eficiência dos mercados, e refutar a eficiência, com fraca ligação com os preços à vista, resulta em baixa efetividade do hedge e problemas na descoberta de preços. Mas, segundo esses autores, são, naturalmente, características esperadas em mercados futuros recentes de economias emergentes. A compreensão da eficiência nos mercados futuros possibilita aos policy makers implementarem melhores políticas agrícolas, monitoramento efetivo de especulações, assim como da proteção aos riscos de preços, de forma a melhorar tanto a liquidez como a eficiência (ZHENG e WANG, 2013).

\section{Considerações finais}

Demonstraram-se evidências favoráveis à hipótese de diferença martingal nos mercados de soja e seus derivados na bolsa CBT, bem como para o óleo de soja, negociado na NCD. Todos os testes de razão de variância efetuados nesses mercados indicaram que são informacionalmente eficientes, com respeito à hipótese fraca de eficiência de mercado. O eficiente funcionamento justifica a falta de intervenções governamentais, além de motivar novos contratos com base nas experiências bem sucedidas desses mercados informacionalmente eficientes. Depreende-se, portanto, na utilidade social destes aos agentes, os quais têm nesses mercados a possibilidade de descoberta de preços, diminuição dos custos de transação, gestão dos estoques e dos riscos de preços.

Acredita-se que as intervenções governamentais geram ruídos e refletem nas expectativas dos agentes que se utilizam, direta ou indiretamente, dos demais mercados. Impactam na acurácia dos preços, os quais deveriam representar o equilíbrio do mercado, além de elevar a quantidade de buscas por informações dos agentes. A falta de fluxo informacional adequado justifica alterações contratuais executadas pelas bolsas, no intuito de propiciarem a descoberta de preços nesses mercados cujas evidências são desfavoráveis à eficiência fraca de mercado.

As dependências similares dos mercados podem ser consideradas como efeito espraiamento da eficiência informacional. Os agentes devem, portanto, manter percepções em relação aos diversos mercados devido às sinalizações interdependentes dos preços. Os clusters de dependências lineares podem proporcionar relevantes informações entre os participantes desses clusters. Além das sinalizações contidas nos preços desses mercados, podem servir como proteção ao risco nas transações internacionais das commodities.

As evidências dos testes de razão de variância - aparentemente contraditórias - podem ter como causa outros fatores além das dependências lineares nos mercados de commodities. Acredita-se que essas evidências podem ser ocasionadas, por exemplo, pela existência de previsibilidade temporária nos retornos. E essa previsibilidade temporária, em um arcabouço teórico de eficiência dos mercados, com a adaptação dos agentes a essas previsibilidades temporárias, é um possível caminho a estudos subsequentes.

\section{Referências}

ABITANTE, K. G. Co-integração entre os mercados spot e futuro: evidências dos mercados de boi gordo e soja. Revista de Economia e Sociologia Rural, v. 46, n. 1, p. 75-96, 2008. 
ARUGA, K. Market efficiency in the non-genetically modified soybean futures market. Journal of Agricultural \& Food Industrial Organization, v. 9, n. 1, p. 1-11, 2011.

BASTOS, J. A. e CAIADO, J. Clustering financial time series with variance ratio statistics. Quantitative Finance, v. 14, n. 12, p. 2121-2133, 2014.

BELAIRE-FRANCH, G. e CONTRERAS, D. Ranks and signs-based multiple variance ratio tests. In: SPANISH-ITALIAN MEETING ON FINANCIAL MATHEMATICS, VII., 2004, Cuenca. Anais... Cuenca: Spanish-Italian Meeting on Financial Mathematics, 2004. p. 40.

CHINN, M. D. e COIBION, O. The predictive content of commodity futures. Journal of Futures Markets, v. 34, n. 7, p. 607-636, 2014.

CHOW, K. e DENNING, K. C. A simple multiple variance ratio test. Journal of Econometrics, v. 58, n. 3, p. 385-401, 1993.

CONT, R. Empirical properties of asset returns: stylized facts and statistical issues. Quantitative Finance, v. 1, n. 2, p. 223-236, 2001.

DUDA, R. O., HART, P. E. e STORK, D. G. Pattern Classification. New York: John Wiley \& Sons, 2001.

ESCANCIANO, J. C. e LOBATO, I. N. Testing the martingale hypothesis. In: MILLS, T. C. e PATTERSON, K. (Orgs.). Palgrave handbook of econometrics volume 2: applied econometrics. New York: Palgrave Macmillan, 2009.

FAMA, E. F. Efficient capital markets: a review of theory and empirical work. The Journal of Finance, v. 25, n. 2, p. 383-417, 1970.

FISHER, T. J. e GALLAGHER, C. M. New weighted portmanteau statistics for time series goodness of fit testing. Journal of the American Statistical Association, v. 107, n. 498, p. 777-787, 2012.

FRAGA, G. J. e SILVA NETO, W. A. Eficiência no mercado futuro de commodity: evidências empíricas. Revista Econômica do Nordeste, v. 42, n. 1, p. 125-137, 2011.

GARCIA, P., HUDSON, M. A. e WALLER, M. L. The pricing efficiency of agricultural futures markets: an analysis of previous research results. Southern Journal of Agricultural Economics, v. 20, n. 1, p. 119-130, 1988.

GARCIA, P. e LEUTHOLD, R. M. A selected review of agricultural commodity futures and options markets. European Review of Agricultural Economics, v. 31, n. 3, p. 235-272, 2004.

JARROW, R. A. e LARSSON, M. The meaning of market efficiency. Mathematical Finance, v. 22, n. 1, p. 1-30, 2012.
KELLARD, N. et al. The relative efficiency of commodity futures markets. The Journal of Futures Markets, v. 19, n. 4, p. 413-432, 1999.

KUMAR, B. e PANDEY, A. Market efficiency in Indian commodity futures markets. Journal of Indian Business Research, v. 5, n. 2, p. 101-121, 2013.

LIAO, T. W. Clustering of time series data - a survey. Pattern Recognition, v. 38, p. 1857-1874, 2005.

LO, A. W. e MACKINLAY, A. C. Stock market prices do not follow random walks: evidence from a simple specification test. Review of Financial Studies, v. 1, n. 1, p. 41-66, 1988.

McKENZIE, A. M. e HOLT, M. T. Market efficiency in agricultural futures markets. Applied Economics, v. 34, n. 12, p. 1519-1532, 2002.

PACHECO, J. M. El carácter aleatorio del Mercado de Futuros ISR. un análisis de series de tiempo. Bolsa de Comercio de Rosario, Lecturas, v. 8, p. 73-114, 2004.

PENG, W., YONG, I. e SUO, R. Commodity futures market in mainland China: recent developments and issues. China Economic Issues, v. 06, p. 1-25, 2006.

ROSS, S. A. Neoclassical Finance. Princeton: Princeton University Press, 2004.

SAHAI, A. K. Efficiency tests of refined soy oil futures in India. International Journal of Research in Management \& Technology, v. 4, n. 2, p. 96-103, 2014.

SHIMODAIRA, H. An approximately unbiased test of phylogenetic tree selection. Systematic Biology, v. 51, n. 3, p. 492-508, 2002.

. Approximately unbiased tests of regions using multistep-multiscale bootstrap resampling. The Annals of Statistics, v. 32, n. 6, p. 2616-2641, 2004.

SUZUKI, R. e SHIMODAIRA, H. Pvclust: an r package for assessing the uncertainty in hierarchical clustering. Bioinformatics, v. 22, n. 12, p. 1540-1542, 2006.

WANG, H. H. e KE, B. Efficiency tests of agricultural commodity futures markets in China. Australian Journal of Agricultural and Resource Economics, v. 49, n. 2, p. 125-141, 2005.

WRIGHT, J. H. Alternative variance-ratio tests using ranks and signs. Journal of Business $\mathcal{E}$ Economic Statistics, v. 18, n. 1, p. 1-9, 2000.

$\mathrm{XU}, \mathrm{R}$. e WUNSCH, D. Survey of clustering algorithms. IEEE Transactions on Neural Networks, v. 16, n. 3, p. 645-678, 2005.

ZHENG, S. e WANG, Z. Pricing efficiency in the chinese NGM and GM soybean futures market. China: An International Journal, v. 11, n. 3, p. 48-67, 2013. 


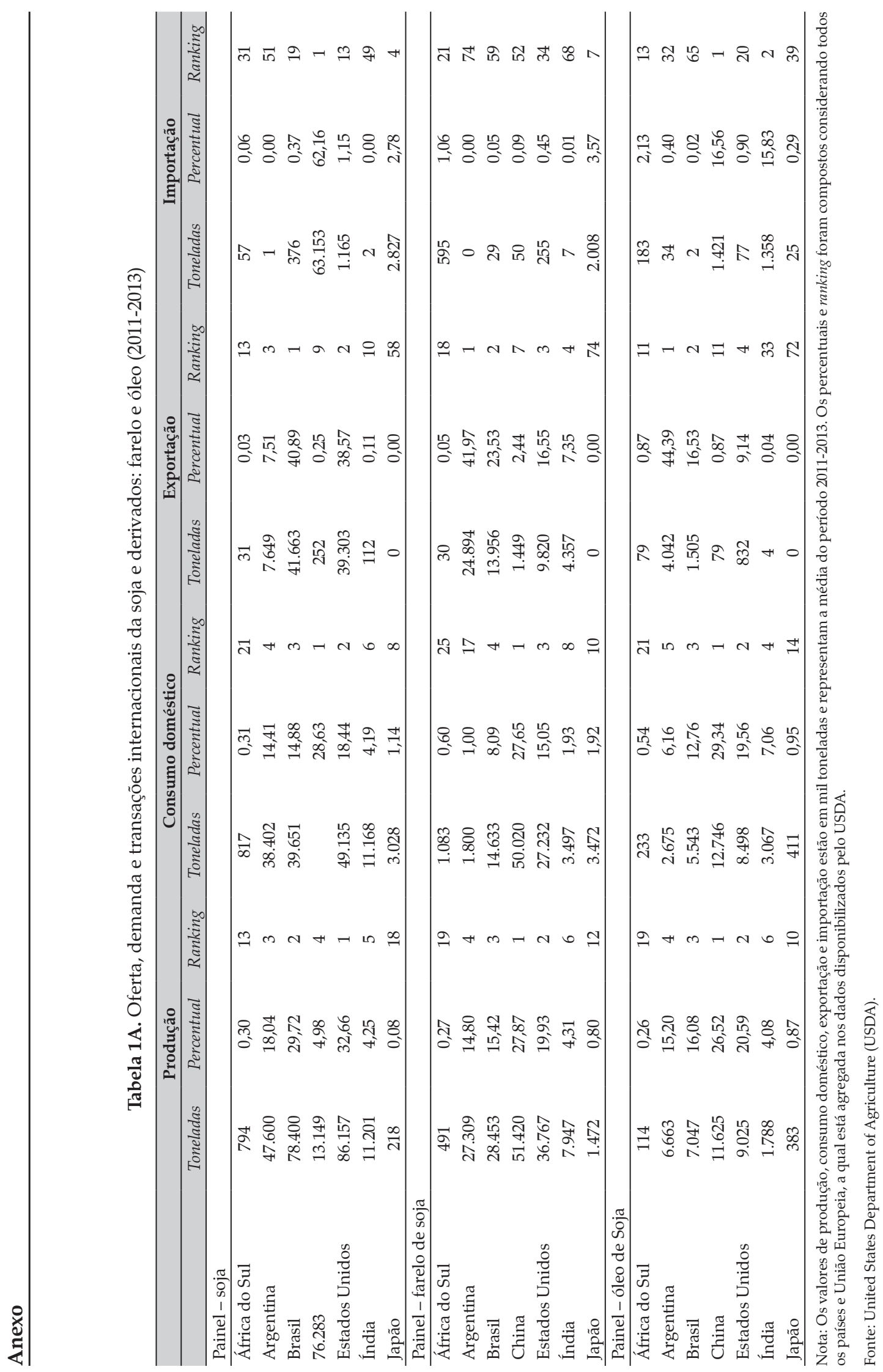

